\title{
Flow and Protein Concentration of Lymph from Lungs of Lambs Developing Hyaline Membrane Disease
}

\author{
I. C. S. NORMAND†, E. O. R. REYNOLDS, L. B. STRANG, and J. S. WIGGLESWORTH \\ From the Department of Paediatrics, University College Hospital Medical School, London W.C.1, \\ and the Nuffield Neonatal Research Unit, Hammersmith Hospital, London W.12
}

Wide tissue septa and dilated lymphatics can be seen in histological sections from the lungs of infants dying from hyaline membrane disease (Wade-Evans, 1962; Balis, Delivoria, and Conen, 1966). These might be produced either by the excessive transfer of liquid from the plasma to the lung interstices, or by the defective clearance of the liquid which normally fills the potential airspaces of the fetal lung. Indeed, both these processes may occur. Liquid and proteins are normally cleared from interstitial spaces through lymphatics, and in the lamb at the onset of breathing there is a large increase in pulmonary lymph flow, which is responsible for the removal of much of the fetal lung liquid (Boston et al., 1965; Humphreys et al., 1967). In the experiments of Humphreys et al. (1967) the increase in pulmonary lymph flow at the start of breathing was smaller in premature lambs, and the decrease in their lung weight after 2 hours of ventilation was less than in mature animals. Unasphyxiated immature lambs delivered at about 125-130 days of gestation (term is at approximately 147 days) develop a clinical and histological picture which seems indistinguishable from that seen in hyaline membrane disease in the human infant (Reynolds et al., 1965a).

The present paper describes the histological appearances of the lungs of immature and mature lambs in which lymph flow measurements were made, with special reference to atelectasis, hyaline membrane formation, and the appearance of the tissue septa and lymphatics. The histology and lymph flow measurements are related to the surface tension characteristics of lung extracts.

\section{Material and Methods}

Anaesthesia was induced in pregnant ewes with

\footnotetext{
Received October 27, 1967.

* This work was aided by a grant from the Medical Research Council.

$t$ In receipt of a grant from the Association for the Aid of Crippled Children.
}

intravenous thiopentone $(10 \mathrm{mg} . / \mathrm{kg}$.) and maintained with intravenous sodium pentobarbitone as required. Artificial ventilation of the ewe was performed through a tracheotomy with a Starling pump. The fetal lamb was delivered through a midline incision on to a heated table adjacent to the ewe. The trachea of the lamb was immediately tied to prevent the inspiration of air.

Experiments were performed on groups of 9 immature and 8 mature fetal lambs. The gestational ages of 8 of the immature lambs were known, and ranged from 113 to 126 days (mean 121 days; term is at 147 days). One lamb was assigned to the immature group on the basis of crown-rump length and body weight. The gestational ages of 3 of the mature lambs were known and were 140,141, and 146 days. The remaining lambs in the mature group were considered to be close to term, and 2 of the ewes were in early labour when the experiment was started. There was no overlap between the groups in gestational age (where known) or crown-rump length.

The carotid artery of the fetal lamb was cannulated for the measurement of blood pressure, oxygen $\left(\mathrm{P}_{\mathrm{a}} \mathrm{O}_{2}\right)$, and carbon dioxide $\left(\mathrm{P}_{\mathrm{a}} \mathrm{CO}_{2}\right)$ tensions, and $\mathrm{pH} . \quad \mathrm{P}_{\mathrm{a}} \mathrm{O}_{2}$ was measured with a modified Clarke electrode, $\mathrm{P}_{\mathrm{a}} \mathrm{CO}_{2}$ with a Severinghaus electrode, and $p \mathrm{H}$ with a capillary glass electrode. Rectal temperature was maintained at 38$39^{\circ} \mathrm{C}$.

Lymph from the lungs of the lamb enters the thoracic and right lymph ducts. The lung lymph can be obtained by collecting lymph from both ducts after the exclusion of lymph from other parts of the body. The techniques used in the dissection have been described elsewhere (Humphreys et al., 1967). In 12 lambs the thoracic duct and right lymph duct components of lung lymph were simultaneously collected. In the remainder either the thoracic duct or the right lymph duct component was collected. After a steady flow of lung lymph from the fetal lamb had been established for at least 30 minutes, ventilation was started with a Harvard positive pressure ventilator through a tracheotomy. None of the liquid which filled the fetal lung was allowed to escape. Because exclusion of cardiac lymph had necessitated a median sternotomy it was possible to inspect the surface of the lung during ventilation. A tidal volume was chosen which produced obvious opening of airspaces (about $12 \mathrm{ml}$./kg. body weight) at 
TABLE

Carotid Arterial Oxygen Tension $\left(\mathrm{P}_{\mathrm{a}} \mathrm{O}_{2}\right)$, Carbon Dioxide Tension $\left(\mathrm{P}_{\mathrm{a}} \mathrm{CO}_{2}\right), \mathrm{pH}$, and Mean Blood Pressure in Immature and Mature Lambs During Fetal Period and After 15 minutes, 1 hour, and 2 hours of Ventilation (mean values and ranges are shown)

\begin{tabular}{|c|c|c|c|c|c|c|c|c|}
\hline & & & & \multicolumn{2}{|c|}{ Fetal } & \multicolumn{3}{|c|}{ Ventilation } \\
\hline & & & & Early & Late & 15 Minutes & 1 Hour & 2 Hours \\
\hline Immature & $e\left\{\begin{array}{l}\mathrm{P}_{\mathrm{a}} \mathrm{O}_{2} \mathrm{~mm} \cdot \mathrm{Hg} \\
\mathrm{P}_{\mathrm{a} C \mathrm{O}_{2}} \mathrm{~mm} . \mathrm{Hg} \\
\mathrm{pH} \ldots \\
\mathrm{BP} \mathrm{mm} . \mathrm{Hg}\end{array}\right.$ & $\begin{array}{l}\cdots \\
\cdots \\
\cdots \\
\cdots\end{array}$ & $\begin{array}{l}\cdots \\
\cdots \\
\cdots\end{array}$ & $\begin{array}{c}31(22-39) \\
48(42-57) \\
7 \cdot 30(7 \cdot 24-7 \cdot 35) \\
48(35-58)\end{array}$ & $\begin{array}{c}31(20-38) \\
47(41-53) \\
7 \cdot 29(7 \cdot 24-7 \cdot 32) \\
47(33-57)\end{array}$ & $\begin{array}{c}57(25-156) \\
54(37-65) \\
7 \cdot 24(7 \cdot 18-7 \cdot 30) \\
37(28-43)\end{array}$ & $\begin{array}{c}95(60-178) \\
54(40-62) \\
7 \cdot 26(7 \cdot 12-7 \cdot 30) \\
36(20-43)\end{array}$ & $\begin{array}{c}174(67-465) \\
47(35-59) \\
7 \cdot 27(7 \cdot 24-7 \cdot 28) \\
32(20-37)\end{array}$ \\
\hline Mature & 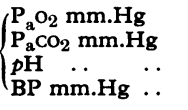 & $\begin{array}{l}\cdots \\
\cdots \\
\cdots\end{array}$ & $\begin{array}{l}\cdots \\
\cdots \\
\cdots \\
\cdots\end{array}$ & $\begin{array}{c}32(28-42) \\
43(39-51) \\
7 \cdot 32(7 \cdot 24-7 \cdot 38) \\
55(46-65)\end{array}$ & $\begin{array}{c}31(27-38) \\
50(43-55) \\
7 \cdot 27(7 \cdot 21-7 \cdot 30) \\
56(46-70)\end{array}$ & $\begin{array}{c}78(41-220) \\
40(32-46) \\
7 \cdot 30(7 \cdot 10-7 \cdot 41) \\
53(43-62)\end{array}$ & $\begin{array}{c}73(44-159) \\
36(31-54) \\
7 \cdot 34(7 \cdot 26-7 \cdot 44) \\
47(35-65)\end{array}$ & $\begin{array}{c}78(50-185) \\
27(18-41) \\
7 \cdot 42(7 \cdot 31-7 \cdot 49) \\
42(28-65)\end{array}$ \\
\hline
\end{tabular}

a respiratory rate of 30 per minute. The end-expiratory pressure was held at $2-4 \mathrm{~cm} . \mathrm{H}_{2} \mathrm{O}$ in mature lambs and at 6-12 cm. $\mathrm{H}_{2} \mathrm{O}$ in immature lambs. In order to avoid hypoxaemia during the start of breathing and to produce comparable blood gas tensions thereafter, $100 \% \mathrm{O}_{\mathrm{z}}$ was used as the ventilating gas in immature lambs, and $50 \% \mathrm{O}_{2}$ in mature lambs. The difference in $\mathrm{O}_{2}$ concentration of the ventilating gas in the two groups of animals was not considered likely to influence the lung pathology, because changes due to oxygen toxicity require many hours or days to develop (Lambertsen, 1965). As a further precaution against hypoxaemia the umbilical cord was not tied until 30 minutes after starting ventilation. After the first 15 minutes of ventilation the tidal volume was adjusted to maintain a $\mathrm{P}_{\mathrm{a}} \mathrm{CO}_{2}$ of about $40 \mathrm{~mm}$. $\mathrm{Hg}$.

Ventilation was continued for 2 hours in 6 of the immature lambs, 1 hour in 2 lambs, and $1 \frac{1}{2}$ hours in 1 lamb. 4 mature lambs were ventilated for 2 hours, and the others for $2 \frac{1}{2}, 4,6$, and 7 hours.

At the conclusion of the period of ventilation the lungs were inflated with a few breaths of room air to avoid atelectasis due to oxygen absorption, the lamb was killed by clamping the aorta and pulmonary artery, and the lungs were excised. Pieces of the upper and lower lobes were fixed in $10 \%$ formol saline or Helly's fluid, blocked in paraffin, sectioned, and stained with Erhlich's haematoxylin and eosin. Additional sections were stained with periodic acid-Schiff, phosphotungstic acid haematoxylin, Feulgen, and elastic Van Gieson techniques. For the measurement of surface tension, lung extracts in saline were prepared from $5 \mathrm{~g}$. pieces of the upper lobes of immature lambs and the lower lobes of mature lambs. Measurements were made in a modified Wilhelmy balance (Brown, Johnson, and Clements, 1959). Details of the method employed are given by Reynolds et al. (1965b). Readings were made of the minimum surface tension during compression of the surface after $2 \frac{1}{2}$ hours of alternate compression and expansion (10 cycles).

Total protein concentrations in plasma and lymph were measured by the method described by Lowry et al. (1951), modified for use with a Technicon auto-analyser.

\section{Results}

Measurements of blood gas tensions, $p \mathrm{H}$, and blood pressure are summarized in the Table. The 'early' fetal values refer to results obtained at the beginning of the dissection (which usually took between 1 and $1 \frac{1}{2}$ hours). 'Late' fetal values were obtained at the end of the fetal lymph collection period and just before ventilation. There were no important differences between values from the mature and immature lambs during the fetal period. After the start of breathing, the $\mathrm{P}_{\mathrm{a}} \mathrm{CO}_{2}$ tended to be higher and the $p \mathrm{H}$ lower in the immature than in the mature lambs, but the $\mathrm{P}_{\mathrm{a}} \mathrm{O}_{2}$ values in the two groups were very similar, presumably because of the higher concentration of $\mathrm{O}_{2}$ used to ventilate the immature lambs.

When ventilation began, the lungs of the mature lambs expanded readily and inspection of the lung surface showed that gas was retained in the airspaces at end-expiration. In contrast, the lungs of the immature lambs could be seen to collapse, resuming their fetal appearance at the end of every breath, even with end-expiratory pressures of 6-12 cm. $\mathrm{H}_{2} \mathrm{O}$.

Fig. 1 shows mean values of lung lymph flow, lymph protein concentration, and protein flow (lymph flow $\times$ protein concentration) before and after the start of breathing. The increases in lymph flow and protein flow with ventilation are both significantly greater in mature than in immature lambs $(p<0.002)$.

The surface tensions of lung extracts from the upper lobes of immature lambs ranged from 18 to 22 dynes $/ \mathrm{cm}$. (mean 21 dynes $/ \mathrm{cm}$.). In mature lambs the surface tensions of the lower lobes varied from 1 to 7 dynes $/ \mathrm{cm}$. (mean 3 dynes $/ \mathrm{cm}$.). Because it has been shown that low surface tensions appear earlier in gestation in extracts from the upper lobes 


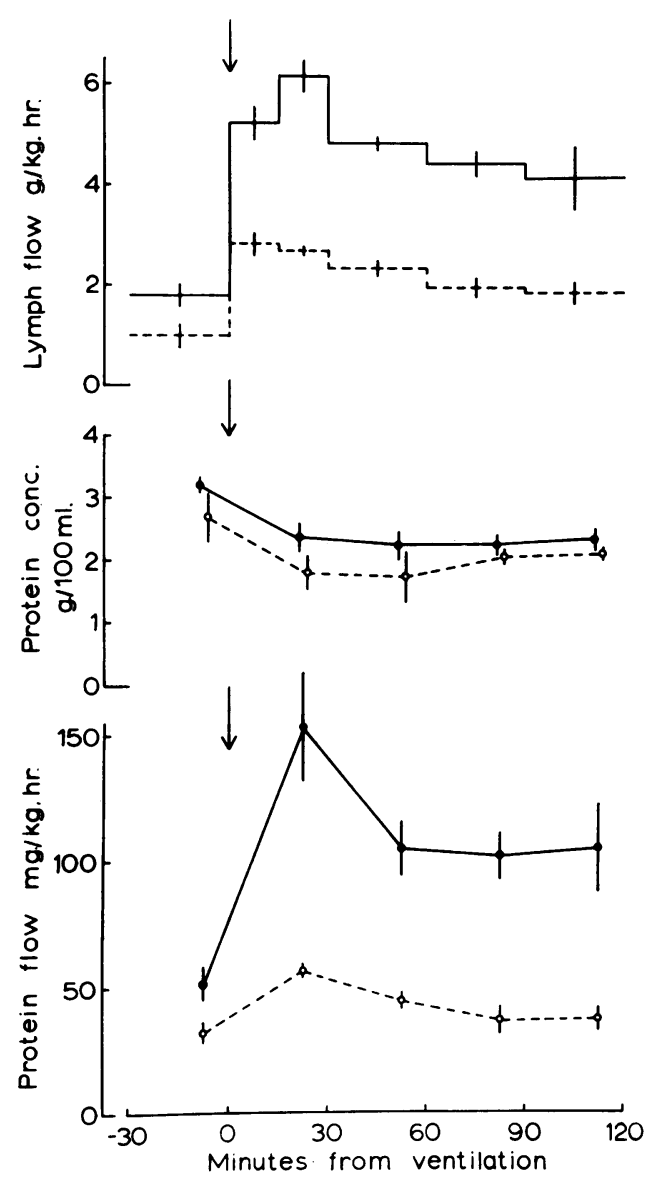

Fig. 1.-Flow rate, protein concentration, and protein flow (concentration $\times$ flow) per kg. body weight in lymph from the lungs of 6 mature and 6 immature lambs before and after the start of ventilation.

The vertical lines indicate $\pm 1 S E$ of the mean. mature lambs; -----, immature lambs. The start of ventilation is indicated by the arrows.

than in the lower lobes in lambs (Howatt et al., 1965), the recorded values were the lowest obtainable for the lungs examined.

Histological examination showed the lungs of the immature lambs to be at the canalicular stage of development (Loosli and Potter, 1959). The alveolar ducts were well developed, with loss of cuboidal epithelium and moderate vascularization of the duct walls but minimal alveolar development. The stage of differentiation was comparable to that seen in premature babies at about 28 weeks of gestation. The terminal bronchioles and alveolar ducts in these animals were dilated to a varying extent, whereas the terminal airspaces showed complete or partial collapse. Interlobular connective tissue spaces were always noted to be wide and contained prominent lymphatic vessels (Fig. 2). A faintly eosinophilic granular background seen in the bronchi, bronchioles, and throughout the airspaces suggested the presence of fluid containing protein. In several lungs there was focal haemorrhage into the subpleural tissue. The lungs of one lamb killed one hour after ventilation at 117 days of gestation showed masses of eosinophilic granular material within dilated bronchioles and alveolar ducts, but no hyaline membrane formation, and the lungs of an animal killed after two hours of ventilation at a gestation of 121 days showed a similar lack of membrane formation. With these exceptions all lungs from the immature lambs showed eosinophilic hyaline material lining the terminal bronchioles and alveolar ducts (Fig. 2, 3, and 4). Masses of similar eosinophilic material plugged many bronchioles (Fig. 3). Hyaline membrane formation had begun in the lungs of the most immature animal of the series (113 days of gestation) within one hour of ventilation. In 2 animals well-defined hyaline membranes were present only in the upper lobe sections, but in one of these there was bronchiolar epithelial necrosis with infiltration by hyaline material in the lower lobe section. Well-developed hyaline membranes contained varying amounts of basophilic granular material shown to be DNA by Feulgen staining and, as in the human infant (Barter, Byrne, and Carter, 1966), were apparently derived from degeneration of bronchiolar epithelium. Engorgement of pulmonary capillaries was seen in the sections showing well-developed membranes and pronounced alveolar collapse (Fig. 4) but not in those showing minimal changes. The lung sections closely resembled those of premature babies with hyaline membrane disease.

The lungs of the mature lambs showed considerable alveolar formation, with well-developed vascularity of the alveolar walls. The airspaces were uniformly expanded two hours after ventilation (Fig. 5). Subpleural, interlobular, and perivascular tissue spaces were less broad than those of the immature group and lymphatic vessels were not so prominent (Fig. 5). There was no indication that protein-containing fluid had been retained within these lungs.

\section{Discussion}

The present experiments confirm the development of hyaline membrane disease in immature lambs, delivered at a stage in gestation before pulmonary surfactant can first be demonstrated in 


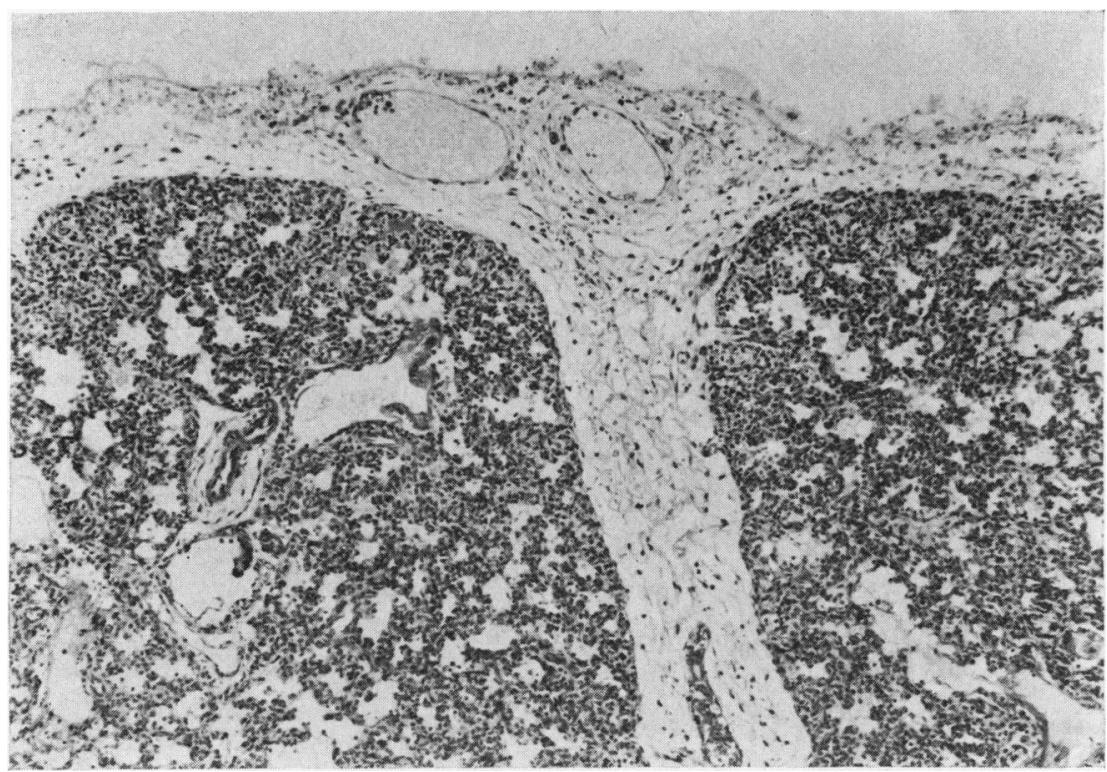

Fig. 2.-Lamb lung. 122 days of gestation, breathed 2 hours. $(H$. and $E . \quad \times 100) \quad$.$A broad interlobular connective$ tissue septum and prominent subpleural lymphatics can be seen. The parenchyma shows dilatation of alveolar ducts and terminal bronchioles, with early hyaline membrane formation.

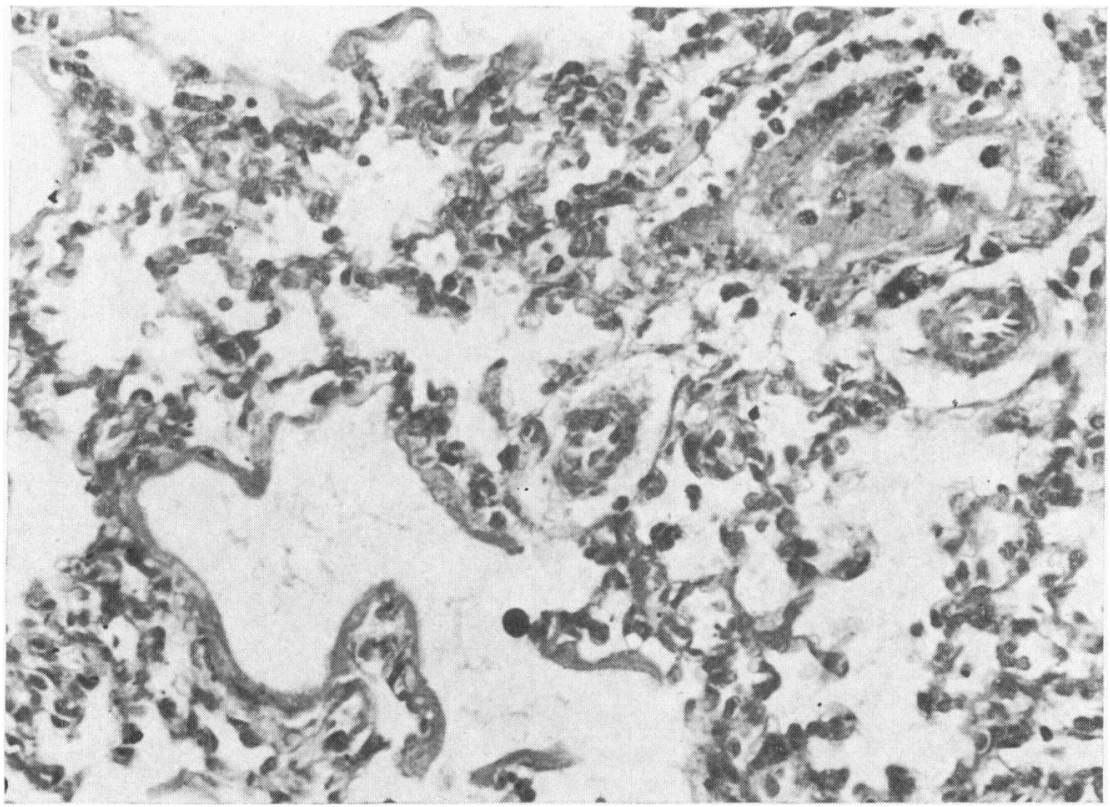

FIG. 3.-Lamb lung. 124 days of gestation, breathed 2 hours. $(H$. and $E . \quad \times 400$.$) Section from an upper lobe$ showing well-defined hyaline membrane in a dilated alveolar duct (lower left) and a mass of cell debris and hyaline material plugging a bronchiole (upper right). 


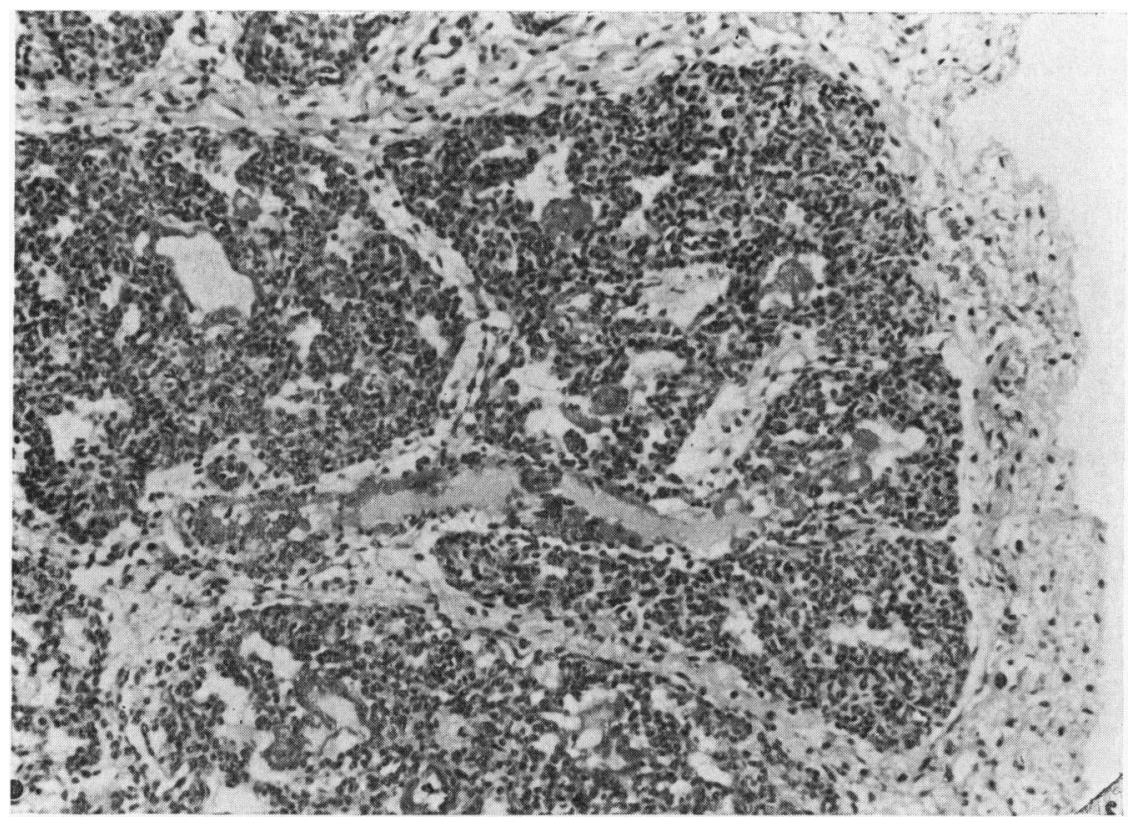

Fig. 4.-Lamb lung. 122 days of gestation, breathed 2 hours. $(H$. and $E . \quad \times 180$.$) Resorption atelectasis with$ alveolar duct dilatation and hyaline membrane formation are visible. The alveolar capillaries are engorged.

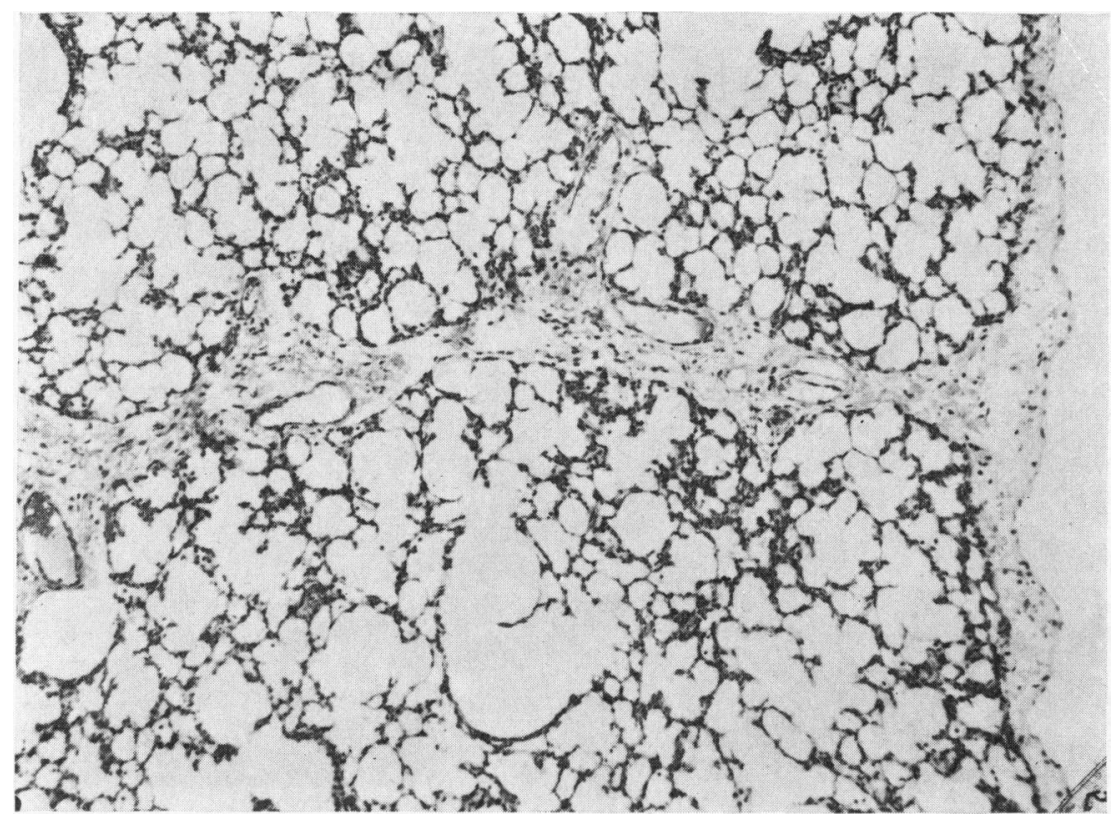

FIG. 5.-Lamb lung. 147 days of gestation, breathed 2 hours. $(H$. and $E . \quad \times 100$.$) \quad Evenly expanded mature lung$ tissue. Interlobular subpleural and connective tissue is not prominent. Compare with Fig. 2. 
the lung (Reynolds et al., 1965a). In the lamb, as in the human infant (Avery and Mead, 1959; Pattle et al., 1962; Reynolds et al., 1965b), it appears probable that the most important factor in the aetiology of hyaline membrane disease is deficiency of pulmonary surfactant.

In the present investigation it was possible to achieve more satisfactory gas exchange than in the study of Reynolds et al. (1965a), probably because the chest had been opened and high inflating pressure could be used without cardiovascular embarrassment. Measurements of blood gas tensions and $p \mathrm{H}$ shown in the Table provide further evidence that the disease can develop in lambs without significant hypoxaemia, hypercapnia, or acidosis in the fetal state. Nor was there any greater degree of hypoxaemia after the start of ventilation in the immature than in the mature animals.

As compared with the mature lamb, the immature lamb which is developing hyaline membrane disease clears less liquid and protein from the lungs through the lymphatics, and protein-containing liquid is retained in the interstitial tissue of the lung. The origin of the retained liquid cannot be decisively determined by the present experiments. A proportion must be fetal alveolar liquid displaced to the lung interstices at the start of ventilation and mixed with interstitial fluid already present in this site. It is also possible that transfer of excess protein and liquid from the plasma into the distended interstitial pool is taking place, even though the total lymph flow from the lungs is less than in the mature lambs. The fall in the protein concentration of lung lymph in both mature and immature lambs when ventilation begins can be accounted for by the transfer of alveolar liquid, which contains only $25 \mathrm{mg}$. $/ 100 \mathrm{ml}$. of protein (Humphreys et al., 1967), to the interstitial space.

The high surface tension at the air-liquid interface in the alveoli will produce atelectasis (Avery and Mead, 1959; Clements, 1962), but in addition it probably accounts for the reduced clearance of lung liquid in the immature lamb. At the end of each breath it is likely that liquid displaced into the interstitial tissues of the lung during inspiration will be sucked back into the airspaces, and also that liquid will be held in the tissue spaces. A further result of the high surface tension might be transudation of fluid from capillaries, as suggested by Pattle (1958). In the special conditions which exist at the onset of ventilation, where the interstitial spaces of the lungs are flooded with liquid from the alveoli, an important effect of high intra-alveolar surface tension could be retention of this liquid.

\section{Summary}

The flow rate and protein concentration in lymph from the lungs of mature and immature lambs have been studied before and after the start of breathing.

The immature, surfactant-deficient lambs developed histological lesions identical with those seen in human infants dying from hyaline membrane disease, in the absence of asphyxia.

The flow rate and protein flow in lymph from the lungs increased less after the start of breathing in immature lambs developing hyaline membrane disease than in mature lambs.

It is concluded that there is delayed removal of fetal lung liquid and retention of protein in the lungs of lambs that are developing hyaline membrane disease.

The technical assistance of Mr. C. M. J. Bright and Miss Elizabeth Kifford is gratefully acknowledged. The photomicrographs were prepared by Mr. W. Brackenbury.

\section{REFERENCES}

Avery, M. E., and Mead, J. (1959). Surface properties in relation to atelectasis and hyaline membrane disease. Amer. F. Dis. Child., 97, 517.

Balis, J. U., Delivoria, M., and Conen, P. E. (1966). Maturation of postnatal human lung and the idiopathic respiratory distress syndrome. Lab. Invest., 15, 530.

Barter, R. A., Byrne, M. J., and Carter, R. F. (1966). Pulmonary hyaline membrane: late results of injury to the lung linings. Arch. Dis. Childh., 41, 489.

Boston, R. W., Humphreys, P. W., Reynolds, E. O. R., and Strang L. B. (1965). Lymph-flow and clearance of liquid from the lungs of the foetal lamb. Lancet, 2, 473.

Brown, E. S., Johnson, R. P., and Clements, J. A. (1959). Pulmonary surface tension. F. appl. Physiol., 14, 717.

Clements, J. A. (1962). Surface phenomena in relation to pulmonary function. Physiologist, 5, 11.

Howatt, W. F., Avery, M. E., Humphreys, P. W., Normand, I. C. S., Reid, L., and Strang, L. B. (1965). Factors affecting pulmonary surface properties in the fetal lamb. Clin. Sci., 29, 239.

Humphreys, P. W., Normand, I. C. S., Reynolds, E. O. R., and Strang, L. B. (1967). Pulmonary lymph flow and the uptake of liquid from the lungs of the lamb at the start of breathing. f. Physiol. (Lond.), 193, 1.

Lambertsen, C. J. (1965). Effects of oxygen at high partial pressure. In Handbook of Physiology, section 3, Vol. 2, p. 1027. Ed. by W. O. Fenn and H. Rahn. American Physiological Soc., Washington D.C.

Loosli, C. G., and Potter, E. L. (1959). Pre- and postnatal development of the respiratory portion of the human lung. Amer. Rev. resp. Dis., 80, 5.

Lowry, O. H., Rosebrough, N. J., Farr, A. L., and Randall, R. J. (1951). Protein measurement with the Folin phenol reagent. F. biol. Chem., 193, 265.

Pattle, R. E. (1958). Properties, function, and origin of the alveolar lining layer. Proc. roy. Soc. B., 148, 217.

-, Claireaux, A. E., Davies, P. A., and Cameron, A. H. (1962). Inability to form a lung-lining film as a cause of the respiratory distress syndrome in the newborn. Lancet, 2, 469.

Reynolds, E. O. R., Jacobson, H. N., Motoyama, E. K., Kikkawa, Y., Craig, J. M., Orzalesi, M. M., and Cook, C. D. (1965a). The effect of immaturity and prenatal asphyxia on the lungs and pulmonary function of newborn lambs; the experimental production of respiratory distress. Pediatrics, 35, 382.

-, Orzalesi, M. M., Motoyama, E. K., Craig, J. M., and Cook, C. D. (1965b). Surface properties of saline extracts from lungs of newborn infants. Acta Paediat. (Uppsala), 54, 511.

Wade-Evans, T. (1962). The formation of hyaline membranes in the newborn baby. Arch. Dis. Childh., 37, 470. 